\title{
MODELAGEM E SIMULLAÇÃO DO ESCOAMENTO IMISCÍVEL DE ÁGUA E ÓLEO ATRAVÉS DE UM CANAL SOB DIFERENTES CONDIÇÕES OPERACIONAIS
}

\author{
F. MIOTTO ${ }^{1}$, M. B. QUADRI ${ }^{1}$, C. S. GONÇALVES ${ }^{1}$ e D. P. TRAMONTIN ${ }^{1}$ \\ ${ }^{1}$ Universidade Federal de Santa Catarina, Departamento de Engenharia Química e \\ Engenharia de Alimentos \\ E-mail para contato: fabio.miotto@posgrad.ufsc.br
}

\begin{abstract}
RESUMO - O escoamento multifásico em dutos e canais é de extrema importância na indústria do petróleo, envolvendo desde operações de exploração até de transporte. A complexidade deste tipo de problema consiste em se descrever a movimentação da interface e a fluidodinâmica das fases. O escoamento de óleo e água, através de um canal de seção constante, produz uma interface líquido-líquido. O comportamento dessa interface é analisado com o emprego do método Level Set e das equações de Navier-Stokes e da continuidade, segundo um esquema de elementos finitos implementado no software COMSOL Multiphysics $4.3 \mathrm{~b}$. Três geometrias foram consideradas, avaliando-se: a influência da velocidade de injeção, a perturbação causada pela presença de uma placa de orifício, o efeito da proporção dos fluidos no domínio e os padrões de escoamento resultantes. O modelo reproduziu comportamentos análogos aos apresentados por outros autores, observando-se escoamentos dos seguintes tipos: ondas rolantes, estratificado liso e ondulado.
\end{abstract}

\section{INTRODUÇÃO}

O escoamento multifásico em dutos e canais são comuns na indústria de petróleo, principalmente na extração e transporte em oleodutos. A complexidade deste tipo de escoamento é inerente à diversidade de arranjos espaciais que as fases podem apresentar (ALWAHAIBI et al, 2012; Xu, X.-X, 2007).

As características onde ocorre o escoamento, sejam elas condições operacionais, geométricas e propriedades físicas das fases combinadas, determinam certas classes de configurações interfaciais, normalmente denominadas regime ou padrão de escoamento multifásico (Paiva, 2011).

É desejável conhecer o tipo de escoamento em determinado sistema, para, desta forma, adaptar o sistema e minimizar o impacto causado pela ocorrência de problemas decorrentes do escoamento multifásico.

\section{MODELAGEM E SIMULAÇÃO}

A modelagem e simulação do escoamento multifásico foi realizada com o emprego do software COMSOL Multiphysics 4.3b. O método Level Set, que é capaz de tratar eficazmente 
mudanças topológicas e/ou descontinuidades que podem incidir no decorrer da propagação de curvas e superfícies em diferentes cenários físicos, como é o caso de uma interface entre dois líquidos imiscíveis (COMSOL, 2013; Osher e Fedkiw, 2003; Sapiro, 2001; Sethian, 1988;).

O padrão de fluxo depende principalmente das velocidades, fração das fases, disposição e geometria do duto onde ocorre o escoamento e das propriedades dos fluidos (AL-WAHAIBI et al, 2012). A Figura 1 apresenta os diferentes padrões de fluxo observados em experimentos de escoamentos horizontais com diferentes velocidades de água e óleo (YUSUF et al, 2012)
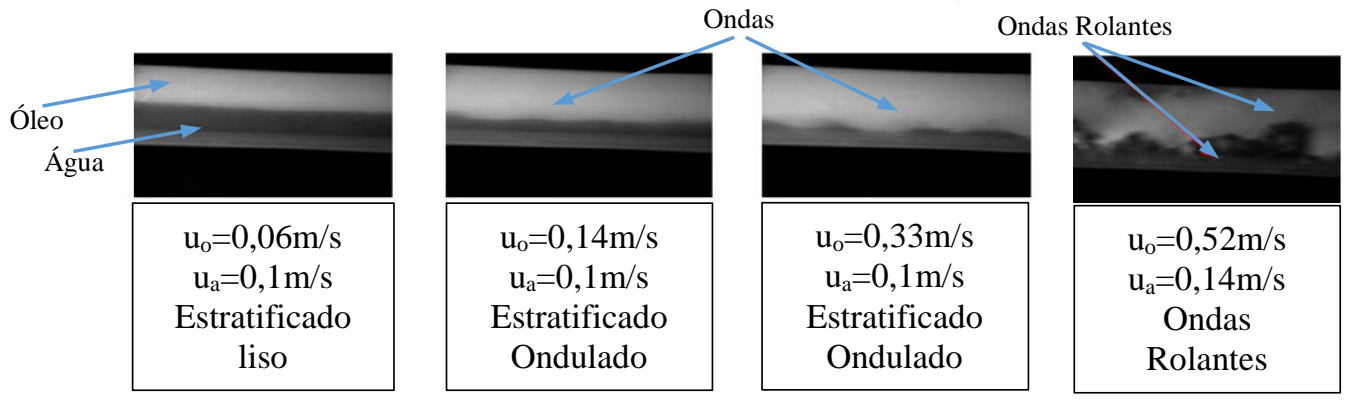

Figura 1 -Padrões de escoamento bifásico água-óleo

O comportamento da interface é analisado estabelecendo várias velocidades de entrada de óleo e de água, velocidades iguais e diferentes dos fluidos em dois modelos deslocando a interface. Um terceiro domínio foi considerado, uma passagem de um escoamento multifásico por um orifício ou estrangulamento.

\subsection{O método Level Set e Escoamento}

O fenômeno de escoamento de cada fase é governado pela equação de Navier-Stokes modificada e equação da continuidade para fluidos incompressíveis, conforme Equações 1 e 2 , respectivamente. A Equação 1 é resolvida para cada uma das fases.

$$
\begin{aligned}
& \rho \frac{\partial \boldsymbol{u}}{\partial t}+\rho(\boldsymbol{u} \cdot \nabla) \boldsymbol{u}=\nabla \cdot\left[-p I+\mu\left(\nabla \boldsymbol{u}+\nabla \boldsymbol{u}^{T}\right)\right]+\rho g+F_{s t}+F \\
& \nabla \cdot \boldsymbol{u}=0
\end{aligned}
$$

No método Level Set, a interface é representada por um conjunto denominado nível ou isocontorno de uma função definida globalmente, a função Level Set $\phi$. No COMSOL Multiphysics, $\phi$ é uma função de passo liso que é igual a zero (0) e de um domínio de um (1) na outra. Do outro lado da interface, existe uma transição suave a partir de zero a um. A interface é definida pela linha de isocontorno 0,5, ou o Level Set, de $\phi$ (COMSOL, 2013).

O mecanismo da advecção no método Level Set não é feito de modo conservativo, isto implica que a zona delimitada pelo conjunto de nível 0 não é conservada. O movimento é analisado por convecção dos "valores" (níveis) da função, com o campo de velocidade. A Equação 3 que governa o sistema é a equação elementar Level Set (COMSOL, 2013). O modelo Level Set usa um reinicializador, que conserva o método para descrever a convecção na interface entre os fluídos, modificando a equação elementar conforme a Equação 4:

$$
\begin{aligned}
& \frac{\partial \Phi}{\partial t}+\boldsymbol{u} \cdot \nabla \Phi=0 \\
& \frac{\partial \Phi}{\partial t}+\boldsymbol{u} \cdot \nabla \Phi=\curlyvee \nabla \cdot\left(\varepsilon \nabla \Phi-\Phi(1-\Phi) \frac{\nabla \Phi}{|\nabla \Phi|}\right)
\end{aligned}
$$


No modelo apresentado as forças de campo, gravidade, são consideradas através da Equações de Navier-Stokes modificada e equação da continuidade, Equações 1 e 2. Estas são resolvidas de forma acoplada às equações do método Level Set, Equaçoes 3 e 4. Desta forma, as forças de campo são compartilhadas através do vetor velocidade, comum aos dois conjuntos de equações.

\subsection{Escoamento Laminar Bifásico utilizando o método Level Set}

A análise deteve-se em baixas velocidades de escoamento, onde o método Level Set para escoamento laminar pode ser utilizado. O domínio contém apenas duas entradas e uma saída. Em cada uma das entradas foram definidas a velocidade e fração de cada um dos fluídos. Na saída optou-se por definir pressão zero. A Figura 2 apresenta o domínio, entradas, saídas, interface inicial e paredes definidas na modelagem e simulação.

A interface foi deslocada em um dos casos e o estrangulamento aparece em apenas um dos casos. Em todos os modelos estudados utilizou-se condição de não deslizamento na parede, o que é pertinente para este tipo de escoamento.

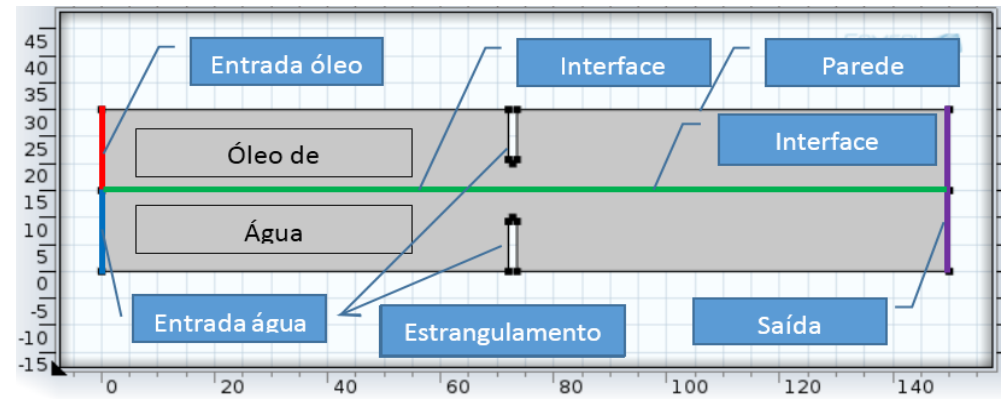

Figura 2 - Geometria do canal

\subsection{Malha}

Para os dois modelos, a malha utilizada foi estabelecida manualmente definindo-se o elemento máximo $(0.6 \mathrm{~mm})$ em cada um dos domínios e, para obter melhor definição na interface, utilizou-se elementos mais refinados $(0.3 \mathrm{~mm})$. Nas duas paredes definidas no modelo foram especificados elementos retangulares, mais adequados para esta parte do domínio. Com as considerações citadas obteve-se uma malha com 49152 elementos.

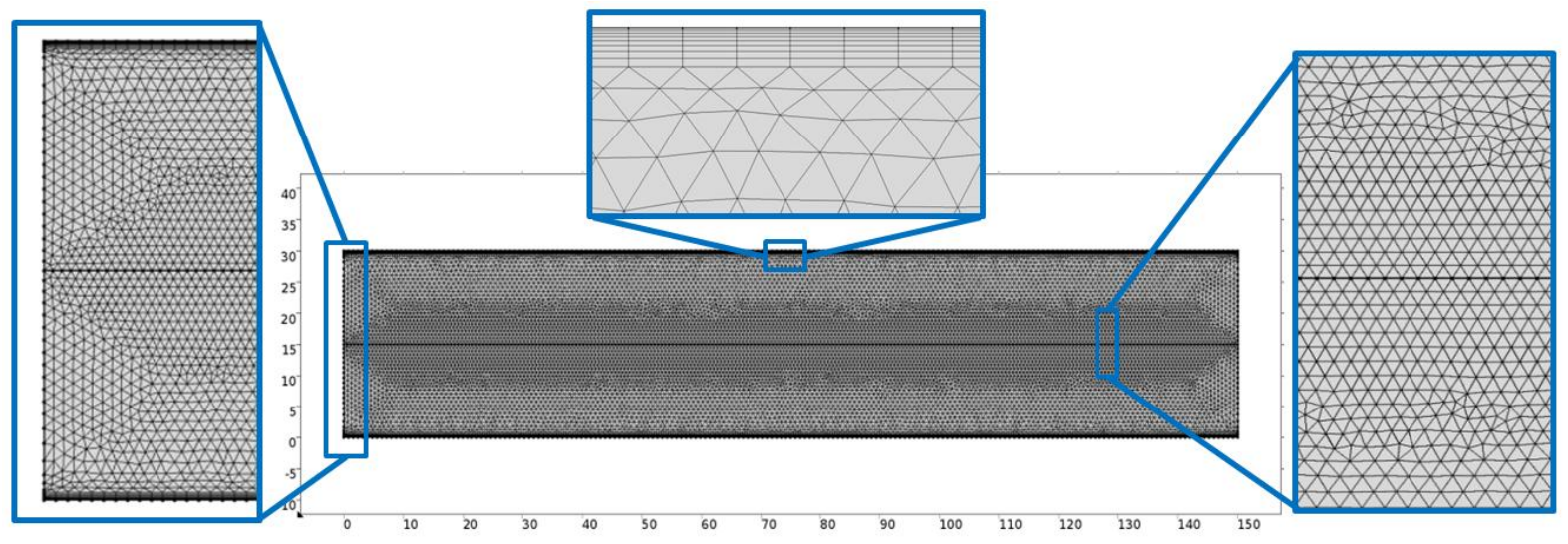

Figura 3: Malha para o modelo de escoamento bifásico no software COMSOL 
Testes anteriores com malha mais grosseira não apresentaram resultado satisfatório, com interface espessa e mal definida. Poderia ser optado por malha mais refinada, porém o ganho não seria muito maior para o resultado, não justificando o custo computacional, e o modelo foi suficiente para fins de observação na disciplina. A Figura 3 apresenta a malha em todo o domínio e um corte nesta para observar melhor os elementos da malha.

\section{RESULTADOS E DISCUSSÃO}

Nesta abordagem, o escoamento multifásico concorrente foi avaliado variando a velocidade de cada um dos fluidos, com velocidades baixas e pouco mais elevadas. Foram utilizadas velocidades iguais e diferentes para os dois fluidos. Em cada um dos escoamentos é possível analisar o padrão de escoamento apresentado e compará-lo aos encontrados na literatura.

\subsection{Escoamento Água-Óleo Em Um Canal}

Escoamento água-óleo - configuração 01. A primeira configuração avaliada descreve a velocidade de entrada de óleo: $0,05 \mathrm{~m} / \mathrm{s}$ e velocidade de entrada de água: $0,05 \mathrm{~m} / \mathrm{s}$. A Figura 4 apresenta o resultado da simulação 5 segundos após a condição inicial.

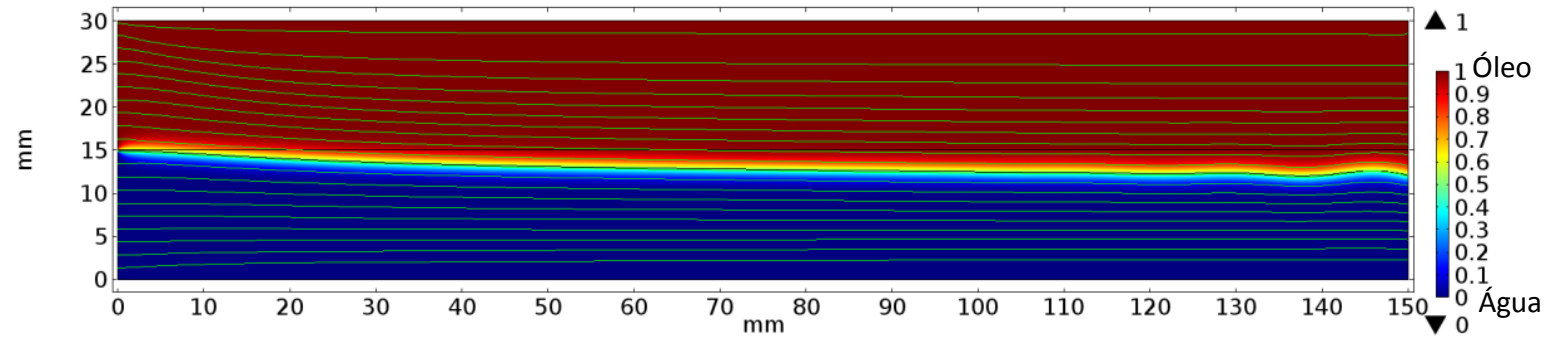

Figura 4: Escoamento Água-Óleo - Configuração 01

A fase óleo, por ser mais viscosa, ocupa um espaço maior do domínio deslocando a água e fazendo com que esta aumente sensivelmente a sua velocidade. A interface, com exceção das extremidades, tem o formato estratificado liso que pode ser comparado aos padrões de escoamento apresentados por Al-Wahaibi et al, (2012) e Yusuf et al, (2012).

Após o processamento, é possível analisar a distribuição de velocidades do escoamento no domínio (Figura 5). Observa-se que o fluxo é reduzido junto às paredes e maior no centro, pouco deslocado pra baixo. É possível verificar que gradualmente ocorre uma aceleração da fase água, menos viscosa, devido à redução do espaço disponível para o escoamento desta, forçada pelo óleo, mais viscoso.

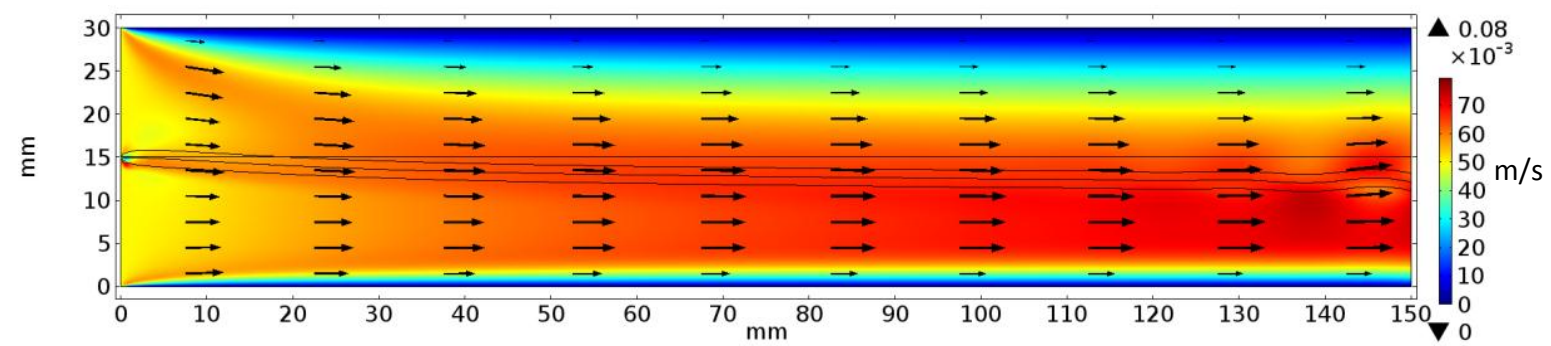

Figura 5 - Distribuição de velocidades no escoamento Água-Óleo - Configuração 01 
Escoamento água-óleo - configuração 02. A segunda configuração avaliada descreve a velocidade de entrada de óleo: $0,5 \mathrm{~m} / \mathrm{s}$ e a velocidade de entrada de água: $0,05 \mathrm{~m} / \mathrm{s}$.

Nesta configuração, o óleo é alimentado a uma velocidade 10 vezes maior que a velocidade da água, o que gera instabilidades e recirculações que acabam arrastando a água. A Figura 6 apresenta o padrão de escoamento obtido com 5 segundos de simulação. Até próximo à metade do caminho, a interface apresenta comportamento ondulado. Com o aumento da velocidade do óleo, na interface formam-se ondas, que avançam formando cristas "rolantes" e que podem se desprender da interface ou se deslocar juntamente com a fase óleo. Este padrão de escoamento apresentado é facilmente comparado às ondas rolantes, conforme citado por Paiva (2011), Al-Wahaibi et al, (2012) e Yusuf et al, (2012).

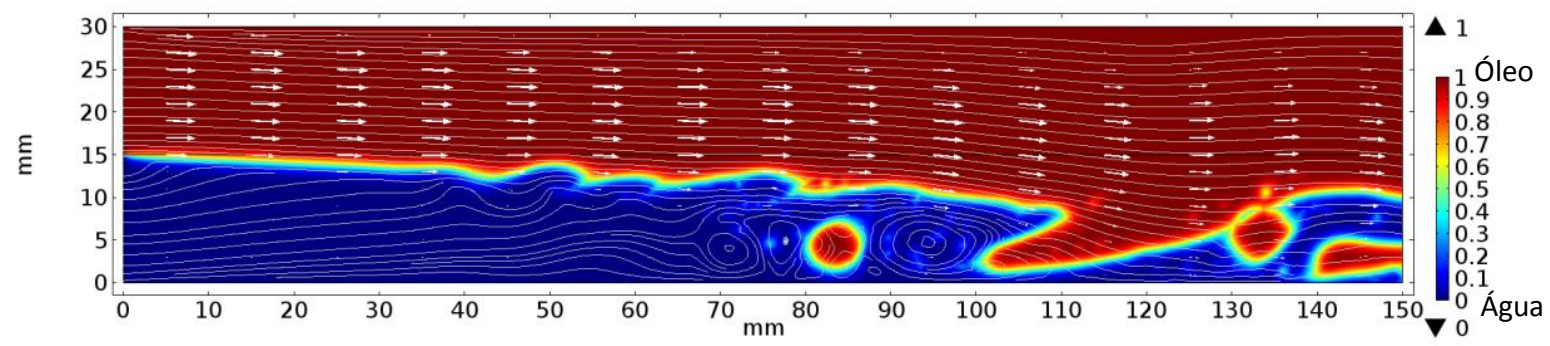

Figura 6: Escoamento Água-Óleo - Configuração 02

A Figura 7 apresenta a correspondente distribuição de velocidades do escoamento no domínio. Observa-se que o fluxo é reduzido junto às paredes e maior no centro do canal. Gradualmente ocorre a aceleração da fase água, impulsionada pelo óleo que é alimentado em uma velocidade maior. Ocorrem também recirculações mesmo em regime laminar.

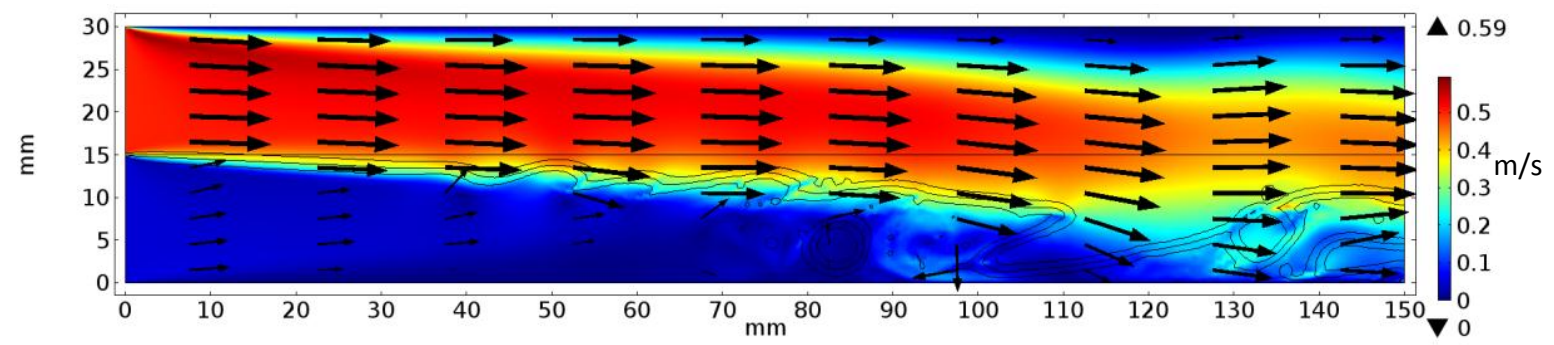

Figura 7 - Distribuição de velocidades no escoamento Água-Óleo - Configuração 02

Escoamento água-óleo - configuração 03. Esta configuração descreve a velocidade de entrada de óleo: $0,25 \mathrm{~m} / \mathrm{s}$ e a velocidade de entrada de água: $0,05 \mathrm{~m} / \mathrm{s}$, com a interface deslocada a fim de avaliar a diferença da posição da interface e da proporção de fluidos no escoamento.

Na Figura 8 a interface é apenas deslocada para baixo devido à diferença de viscosidade e velocidade dos fluidos, apresentando comportamento estratificado liso. Após a fase inicial de acomodação e aceleração da água, esta atua como um "lubrificante" no escoamento do óleo por ser menos viscosa, flui mais facilmente e forma uma camada na parede (PAIVA, 2011; AL-WAHAIBI; ANGELI, P., 2011; AL-WAHAIBI et al, 2012).

A Figura 9 apresenta a distribuição correspondente de velocidades do escoamento águaóleo no canal. O fluxo é reduzido junto às paredes e maior no centro do canal, porém a faixa 
de baixa velocidade é consideravelmente menor na parte inferior do domínio junto à parede, onde o fluido menos viscoso atua como um "lubrificante".

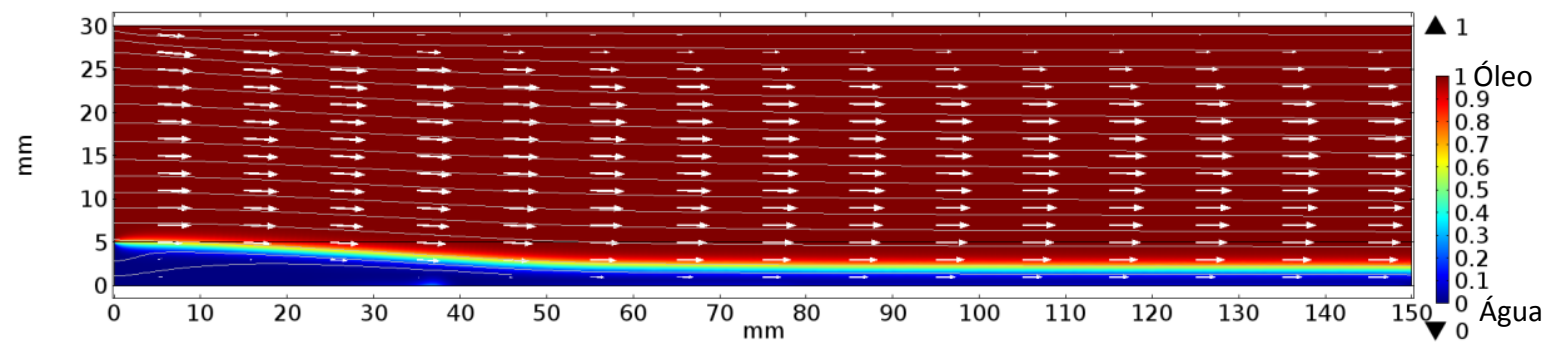

Figura 8: Escoamento Água-Óleo - Configuração 03

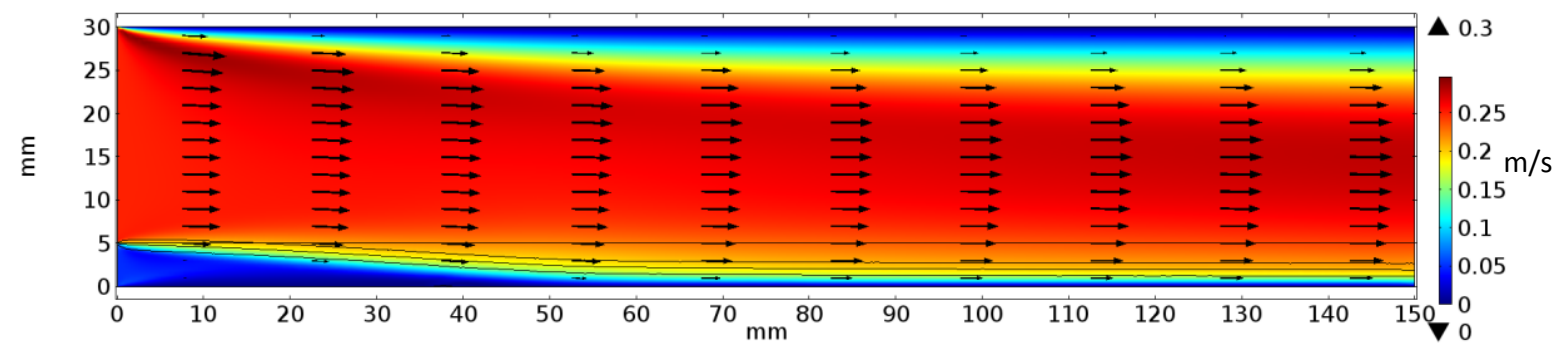

Figura 9 - Distribuição de velocidades no escoamento Água-Óleo - Configuração 03

Escoamento água-óleo - configuração 04. Nesta configuração é possível avaliar as consequências sobre o escoamento causadas pela presença de um estrangulamento. Para a utilização do módulo Level Set laminar, as velocidades de entrada de óleo: $0,01 \mathrm{~m} / \mathrm{s}$ e de entrada de água: $0,01 \mathrm{~m} / \mathrm{s}$, precisaram ser menores que nos outros casos estudados, isto devido à elevada perda de carga e formação de instabilidades.

Na Figura 10 observa-se a formação de vários vórtices, ou instabilidades laminares, após o orifício, e a presença de duas zonas mortas, onde o fluido permanece praticamente parado, já que o estrangulamento modifica as linhas de fluxo e o fluido é forçado a passar pelo orifício. A partir do estrangulamento, a interface começa a formação de ondas impulsionadas pelos vórtices formados e pela perturbação gerada no orifício.

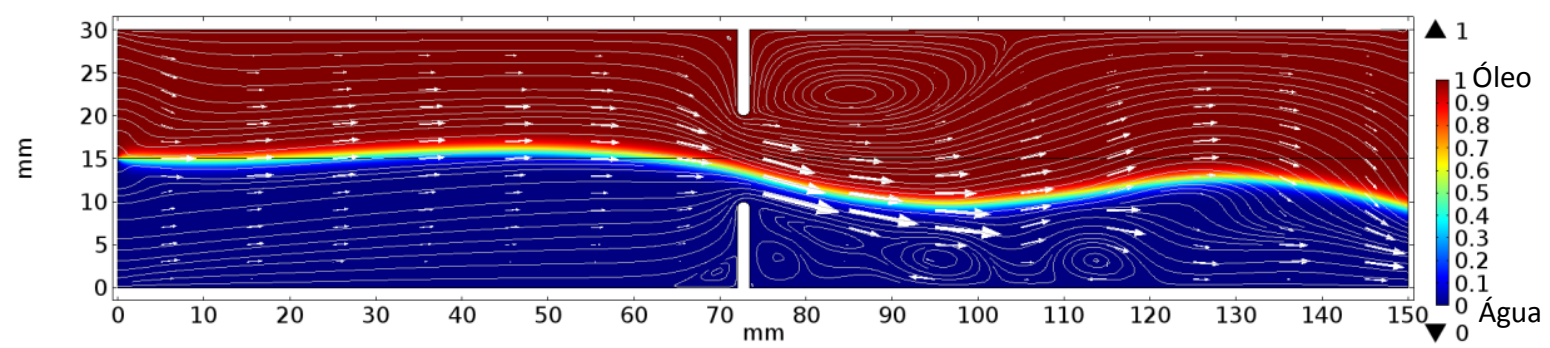

Figura 10: Escoamento Água-Óleo - Configuração 04

Observa-se na Figura 11, que o fluxo é reduzido junto às paredes e maior no centro do canal. Neste caso, a velocidade de injeção é igual para os dois fluidos, porém, devido à diferença de viscosidade, o fluxo é ligeiramente deslocado para baixo, no sentido do fluido menos viscoso. Observa-se que a Magnitude da velocidade é muito maior na interface, e várias correntes de retorno ocorrem, principalmente na parte inferior do domínio. 


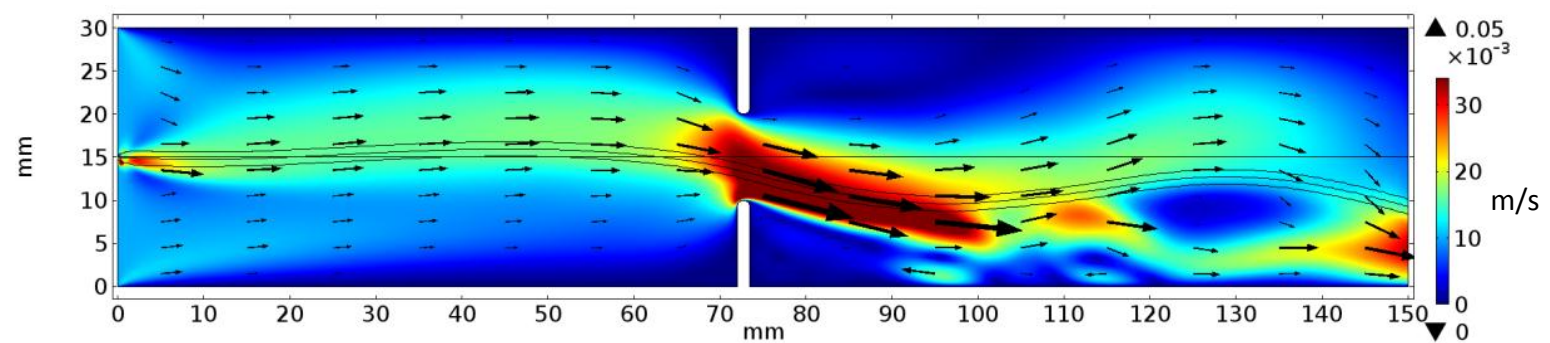

Figura 11 - Distribuição de velocidades no escoamento Água-Óleo - Configuração 04

Escoamento Água-Óleo - Configuração 05. Esta configuração é semelhante à anterior, apenas aumentando-se a velocidade de entrada de óleo para $0,02 \mathrm{~m} / \mathrm{s}$ e mantendo a entrada de água em $0,01 \mathrm{~m} / \mathrm{s}$.

A diferença mais significativa em relação ao caso anterior, é que com o aumento da velocidade do óleo, ocorreu uma redução considerável no tamanho do vórtice formado na fase óleo (Figura 12). Com isso, a interface é ligeiramente deslocada para cima, ao contrário do ocorrido anteriormente.

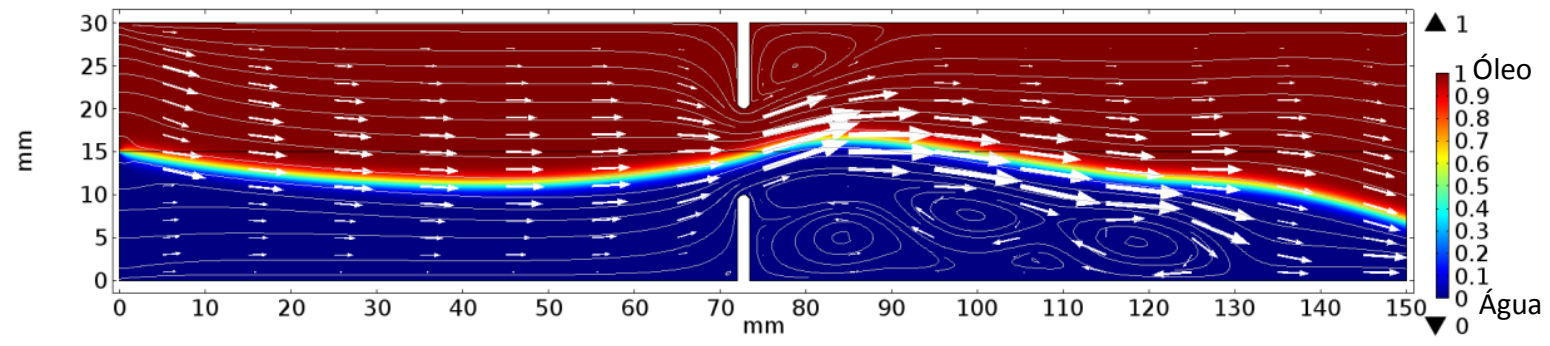

Figura 12: Escoamento Água-Óleo - Configuração 05

Observa-se na Figura 13 que o fluxo é muito semelhante ao apresentado anteriormente. Como, neste caso, a velocidade de injeção do óleo é o dobro daquela utilizada para a água, o fluxo de óleo é intensificado na região da linha média, após passar pelo orifício.

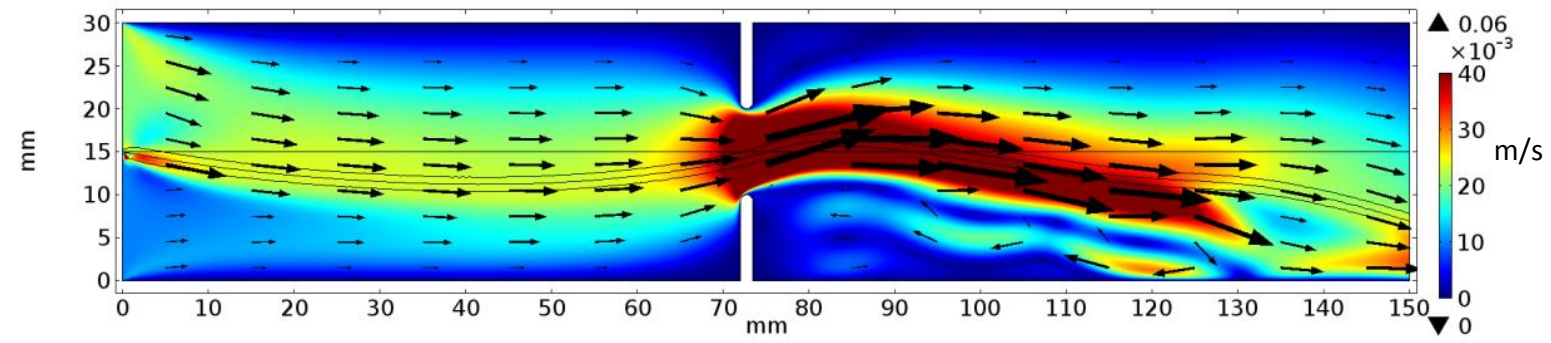

Figura 13 - Distribuição de velocidades no escoamento Água-Óleo - Configuração 05

\section{CONCLUSÃO}

O escoamento estratificado água/óleo através de um canal pode ser comparado com padrões de escoamento multifásico disponíveis na literatura. Alguns padrões como ondas rolantes, regimes estratificado liso e estratificado ondulado puderam ser observados nos casos estudados. Também foi possível constatar a influência da velocidade de injeção dos fluidos, a 
perturbação causada pela presença de um estrangulamento e o impacto sobre a distribuição de velocidades no escoamento estratificado.

\section{VÁRIÁVEIS}

\begin{tabular}{lll} 
Variável & \multicolumn{1}{c}{ Descrição } & \multicolumn{1}{c}{ Unidade } \\
$\rho$ & Densidade & $\mathrm{kg} / \mathrm{m}^{3}$ \\
$\boldsymbol{u}$ & Vetor velocidade & $\mathrm{m} / \mathrm{s}$ \\
$p$ & Pressão & $\mathrm{Pa}$ \\
$g$ & Gravidade & $\mathrm{m} / \mathrm{s}^{2}$ \\
$T$ & Temperatura & $\mathrm{K}$ \\
$t$ & Tempo & $\mathrm{s}$ \\
$\mu$ & Viscosidade & $\mathrm{Pa} / \mathrm{s}$ \\
$F_{s t}$ & Tensão interfacial & $\mathrm{N} / \mathrm{m}$ \\
$F$ & Força & $\mathrm{N} / \mathrm{m}$ \\
$\phi$ & Função Level Set & 0 a 1 \\
$\gamma$ & Parâmetro de reinicializações & $\mathrm{m} / \mathrm{s}$ \\
$\varepsilon$ & Espessura onde $\phi$ varia de 0 a 1 & $\mathrm{~m}$
\end{tabular}

\section{REFERÊNCIAS BIBLIOGRÁFICAS}

AL-WAHAIBI, T.; ANGELI, P. Experimental study on interfacial waves in stratified horizontal oil-water flow. International Journal of Multiphase Flow, 2011.

AL-WAHAIBI, T., et al. "Experimental study on the transition between stratified and nonstratified horizontal oil-water flow." International Journal of Multiphase Flow, 2012.

YUSUF, N., et al. "Effect of oil viscosity on the flow structure and pressure gradient in horizontal oil-water flow." Chemical Engineering Research and Design, 2012.

BIRD, R. B.; STEWART, W. E.; LIGHTFOOT, E. N. Transport Phenomena. Second Edition, John Wiley \& Sons, Inc. 2002, 56 p.

COMSOL. Rising Bubble. Disponível em: http://www.comsol.com/model/rising-bubble-177. Acesso em 07/11/2013.

OSHER, S. J.; FEDKIW, R. P. Level Set Methods and Dynamic Implicit Surfaces. Number 153 in Applied Mathematical Sciences. Springer, 2003.

OSHER, S.; SETHIAN, J. A. Fronts propagating with curvature-dependent speed: Algorithms based on hamilton-jacobi formulations. J. Comp. Phys., 1988.

PAIVA, T. A. Aplicação de técnicas ultra-sônicas para análise de escoamentos multifásicos do tipo líquido-sólido e líquido-sólido-gás. Dissertação de Mestrado. Universidade Federal de Itajubá: Instituto de Engenharia Mecânica. 2011

SAPIRO, G. Geometric Partial Differential Equations and Image Analysis. Cambridge, 2001.

SETHIAN, J. A. Level Set Methods and Fast Marching Methods. Volume 3 of Cambridge Monographs on Applied and Computational Mathematics. Cambridge, 1999.

$\mathrm{Xu}, \mathrm{X} . \mathrm{X}$. "Study on oil-water two-phase flow in horizontal pipelines." Journal of Petroleum Science and Engineering, 2007. 